\title{
Sosialisasi dan Simulasi Perhitungan Listrik Prabayar Di Wilayah Petukangan Utara Jakarta Selatan
}

\author{
Adri Senen $^{1}$; Yoakim Simamora ${ }^{2}$; Tri Wahyu Oktaviana $\mathbf{P}^{3}$; Dwi Anggaini ${ }^{4}$ \\ 1,2,3,4 Teknik Elektro, Sekolah Tinggi Teknik PLN \\ 1ad_senen@yahoo.com
}

\begin{abstract}
ABSTRAK
Program listrik prabayar merupakan terobosan PT. PLN (Persero) yang secara resmi diterapkan di Indonesia pada tahun 2010. Alasan dipakainya sistem listrik prabayar adalah untuk mengatasi permasalahan yang muncul pada listrik pascabayar seperti kesalahan pencatatan meter listrik oleh petugas, pencurian listrik, keterlambatan pembayaran tagihan listrik, dan lain sebagainya. Permasalahan tersebut selain merugikan konsumen juga merugikan PT.PLN (Persero) selaku penyedia dan penyalur energi listrik. Penerapan sistem listrik prabayar mampu menjadikan masyarakat lebih bijak dalam pemakaian listrik karena mereka bisa mengatur sendiri penggunaan listrik sesuai keuangan dan kebutuhan. Akan tetapi masih banyak masyarakat yang tidak mengetahui cara penghitungan listrik prabayar. Berdasarkan hasil survei, lebih dari $60 \%$ responden belum mengetahui cara menghitung listrik prabayar. Oleh karena itu perlu diberikan sosialisasi dan simulasi tentang perhitungan listrik prabayar pada masyarakat. Setelah diberikan sosialisasi dan simulasi perhitungan listrik prabayar, peserta sosialisasi dapat mengetahui serta mengaplikasikan cara penghitungan sehinggadapat menjadi konsumen yang lebih bijak dalam menggunakan energi listrik.
\end{abstract}

Kata kunci: Sosialisasi, PLN, Listrik Prabayar

\begin{abstract}
Prepaid meter program is an innovation from PT. PLN (Persero) that officially implemented in Indonesia in 2010. The reason of using prepaid meter is to overcome problems that arise in postpaid meter such as error in manual recording meters, electricity theft, late payment of electricity bills, and so on. These problems, besides disadvantageous to consumers, are also disadvantageous to PT PLN (Persero) itself as the provider and distributor of electrical energy. The application of prepaid meter systems is able to make people wiser in electricity usage because they can manage their own electricity usage according to their financial and needs. However, there are still many people who do not know how to calculate prepaid meter. Based on the results of the survey, more than $60 \%$ of respondents did not know how to calculate prepaid meter. Therefore, it is necessary to provide socialization and simulations about the calculation of prepaid meter to them. After being given socialization and simulation of prepaid meter calculation, participants can find out and apply the calculation method so they are able to be wiser consumers in term of electricity usage.
\end{abstract}

Keywords: Socialization, PLN, Prepaid Meter 


\section{PENDAHULUAN}

Penerapan sistem listrik prabayar sudah diterapkan di Indonesia oleh PT. PLN Persero [1]. Rencana tersebut telah dicanangkan sejak tahun 2008. Pada tahun 2010 PT. PLN resmi mengubah layanan listrik dari listrik pascabayar ke layanan listrik prabayar [2]. Desa Seruni, Kabupaten Sidoarjo, Jawa Timur adalah desa pertama percontohan kawasan desa listrik prabayar di Indonesia. Alasan diberlakukannya program listrik prabayar adalah untuk mengurangi permasalahan-permasalahan yang terjadi pada penggunaan listrik pascabayar. Permasalahanpermasalahan tersebut selain merugikan konsumen, juga merugikan PT.PLN sebagai penyedia listrik di Indonesia.

Permasalahan terkait penggunaan listrik pascabayar misalnya banyak keluhan konsumen terkait lonjakan tagihan pemakaian listrik yang tidak sesuai dengan yang tercantum pada meteran listrik mereka, sebagai akibat pembacaan meteran yang tidak benar oleh petugas pencatat meteran listrik, kedatangan petugas pencatat meteran pada waktu yang tidak tepat dianggap mengganggu konsumen, pemadaman listrik oleh petugas PLN sebagai akibat konsumen yang telat membayar, dan permasalahan lainnya [3]. Selain itu, masalah yang merugikan PT.PLN akibat listrik pascabayar adalah maraknya pencurian listrik dalam berbagai modus sehingga PT.PLN sebagai penyedia dan penyalur listrik kepada konsumen telah menderita kerugian dalam nominal yang sangat besar [2].

Listrik Prabayar atau yang lebih dikenal dengan sebutan token, selain untuk meminimalisasi aksi-aksi penyimpangan, juga mengajak masyarakat agar lebih bijak dalam menggunakan listrik. Listrik prabayar terbukti membantu konsumen untuk melakukan penghematan pemakaian listrik, pengendalian pemakaian listrik rumah tangga, dan pembayaran pemakaian listrik [4]. Dengan menggunakan listrik prabayar, konsumen hanya perlu membeli pulsa listrik yang harganya mulai dari Rp 20.000,00 di konter terdekat, minimarket, atm, bahkan melalui e-commerce. Sayangnya, belum banyak masyarakat yang memahami berapa banyak listrik yang mereka peroleh dari pulsa listrik yang mereka beli. Oleh karena itu, perlu dilakukan sosialisasi dan simulasi perhitungan listrik prabayar sehingga masyarakat mengetahui cara mengkonversi pulsa listrik atau token ke energi listrik yang diperoleh dan mengetahui cara menghitung konsumsi daya listrik dari berbagai peralatan listrik rumah tangga. Dengan mengetahui perhitungan listrik, diharapkan masyarakat lebih positif menanggapi program PT.PLN (Persero) tentang listrik prabayar dan lebih bijak dalam penggunaan listrik rumah tangga.

Sosialisasi dan simulasi perhitungan listrik prabayar dilakukan oleh dosen-dosen STT PLN sebagai bagian dari Program Kemitraan Masyarakat (PKM). Target peserta atau khalayak sasaran sebagai peserta pada sosialisasi dan simulasi perhitungan Listrik Prabayar adalah civitas akademik dan warga masyarakat wilayah Petukangan Utara, Jakarta Selatan yang berminat pada sistem perhitungan listrik prabayar. Agar kegiatan sosialisasi lebih terarah, dilakukan studi lapangan dengan memberikan kuisioner kepada masyarakat tentang pengetahuan mengenai listrik prabayar.

\section{METODE}

\subsection{Sifat dan Bentuk Kegiatan}

Sosialisasi \& simulasi perhitungan listrik prabayar di wilayah Petukangan Utara Jakarta Selatan dilakukan dalam 1 sesi diikuti oleh 33 peserta. Kegiatan ini meliputi tahapan persiapan dan pelaksanaan sosialisasi dilaksanakan dalam jangka waktu 4 (empat) hari kerja. Setiap peserta akan diberikan materi berupa pengetahuan, keterampilan, dan simulasi. Sebelum kegiatan 
dilaksanakan, dilakukan studi lapangan dengan memberikan kuisioner kepada masyarakat tentang pengetahuan mengenai listrik prabayar. Materi yang akan diberikan pada saat kegiatan sosialisasi adalah materi yang kurang dikuasai masyarakat berdasarkan hasil survei atau kuisioner.

Langkah 1 : Masyarakat sekitar diberikan kuisioner tentang listrik prabayar.

Langkah 2 : Peserta sosialisasi diberikan teori tentang listrik prabayar, perbedaannya dengan listrik pasca bayar, dan cara mengatasi permasalahan pada penggunaan listrik prabayar.

Langkah 3 : Peserta diberikan simulasi perhitungan listrik prabayar dengan mengambil contoh dari beberapa peralatan rumah tangga (lampu pijar, lampu LED, setrika, kulkas, dan lain-lain)

Langkah 4 : Setiap peserta secara berkelompok akan diuji untuk melakukan simulasi listrik prabayar berupa alat-alat rumah tangga yang sering digunakan. Pemberian doorprize dilakukan di sela-sela kegiatan kepada kelompok yang dapat menjawab pertanyaan dari tim PKM.

\subsection{Diagram Alir Kegiatan}

Diagram alir kegiatan dapat dilihat pada Gambar 1 berikut ini.

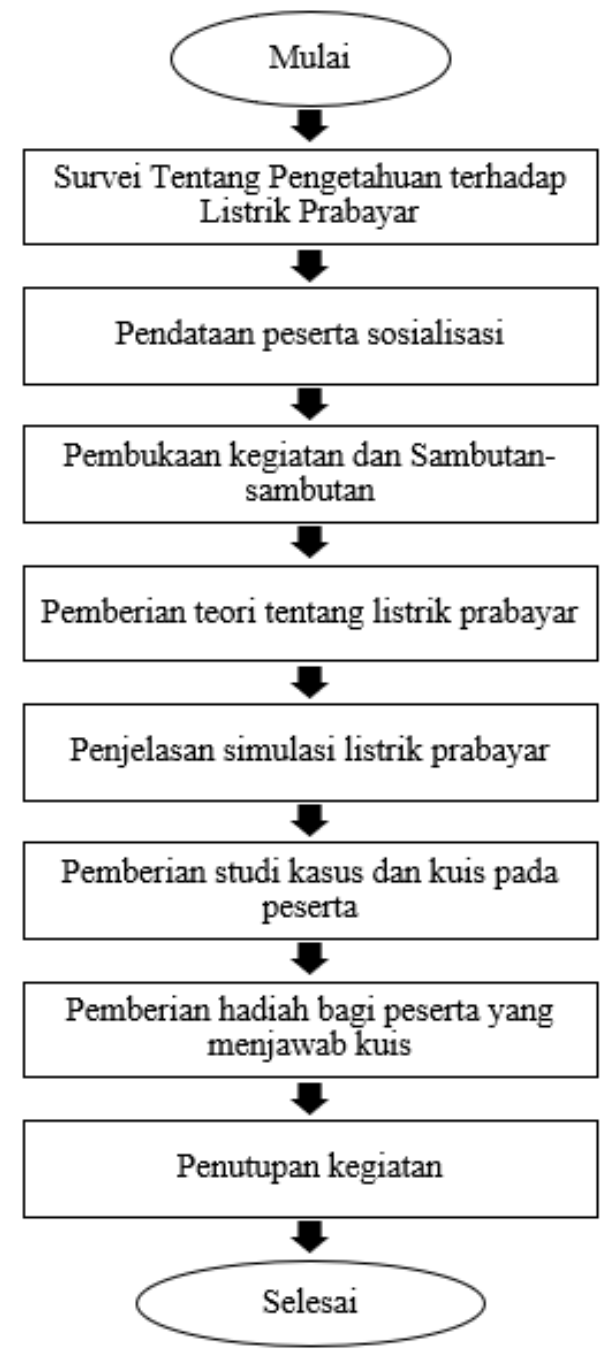

Gambar 1. Diagram Alir Kegiatan Sosialisasi dan Simulasi Perhitungan Listrik Prabayar 


\section{HASIL DAN PEMBAHASAN}

Kegiatan sosialisasi dan simulasi perhitungan listrik prabayar dilaksanakan di Aula SDI Al - Musyarrofah Jakarta dengan peserta adalah masyarakat wilayah Petukangan Utara, Jakarta Selatan. Peserta yang hadir pada kegiatan tersebut sebanyak 33 peserta dari berbagai kalangan dan usia. Sebelum sosialisasi diberikan, peserta diberikan lembar kuisioner untuk diisi sesuai dengan tingkat pemahaman peserta terhadap listrik prabayar. Tujuan pemberian kuisioner adalah untuk mengetahui tingkat pemahaman peserta terhadap listrik prabayar termasuk cara perhitungan listrik prabayar. Dengan mengetahui tingkat pemahaman peserta, pemberian materi sosialisasi menjadi lebih terarah sesuai dengan permasalahan mitra.

Berdasarkan grafik hasil survei pada Gambar 2, 90\% peserta sosialisasi sudah memahami perbedaan listrik prabayar dan pasca bayar. Akan tetapi, berdasarkan grafik Gambar 3, sekitar $63 \%$ responden belum memahami cara konversi rupiah ke KWh pada listrik prabayar. Begitu pula untuk cara perhitungan konsumsi energi listrik yang dipakai pada peralatan listrik di rumah, sebanyak 67\% responden belum memahami cara perhitungannya (Gambar 4). Pada grafik Gambar 5, sebanyak 77\% responden menganggap penting pengetahuan perhitungan listrik prabayar. Dengan demikian dapat ditarik kesimpulan sementara bahwa masyarakat wilayah Petukangan Utara membutuhkan sosialisasi mengenai perhitungan listrik prabayar.

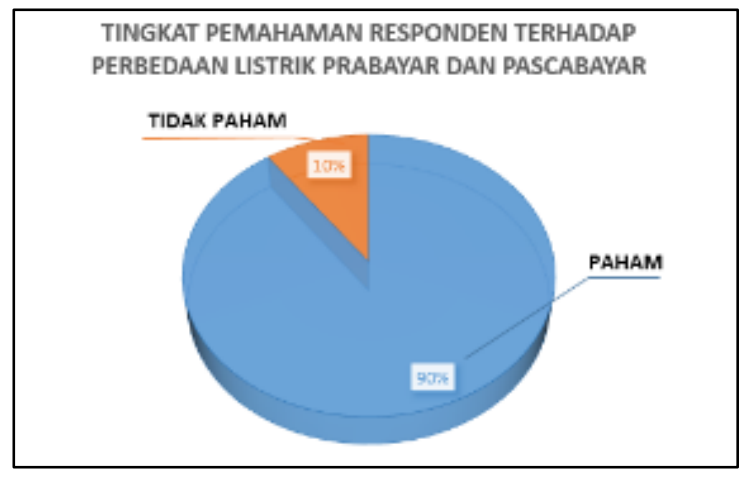

Gambar 2. Hasil Survei Tingkat Pemahaman Responden Terhadap Perbedaan Listrik Prabayar dan Pascabayar

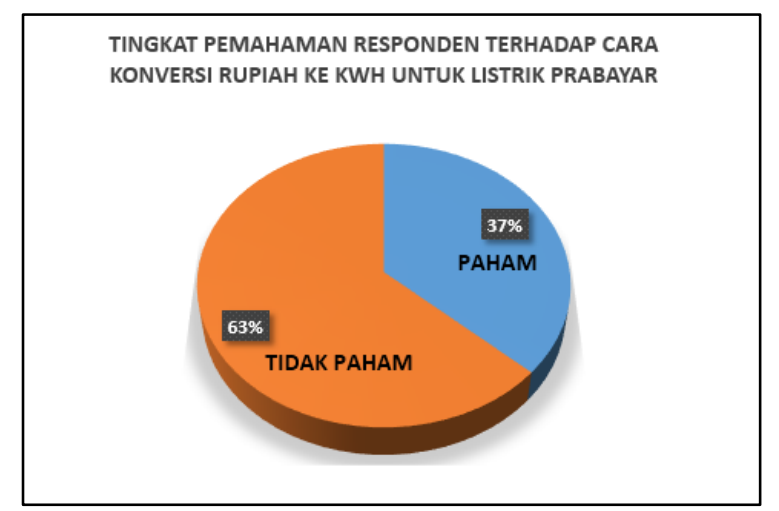

Gambar 3. Hasil Survei Tingkat Pemahaman Responden Terhadap Cara Konversi Rupiah ke KWh untuk Listrik Prabayar 


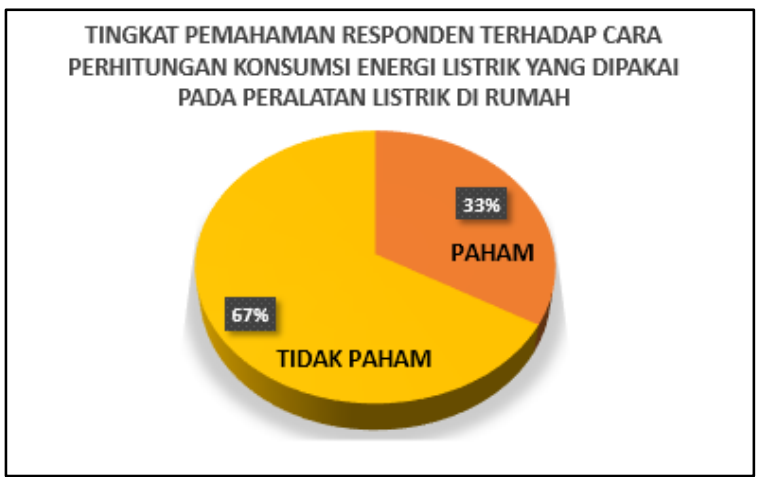

Gambar 4. Hasil Survei Tingkat Pemahaman Responden Terhadap Cara Perhitungan Konsumsi Energi Listrik yang Dipakai pada Peralatan Listrik di Rumah

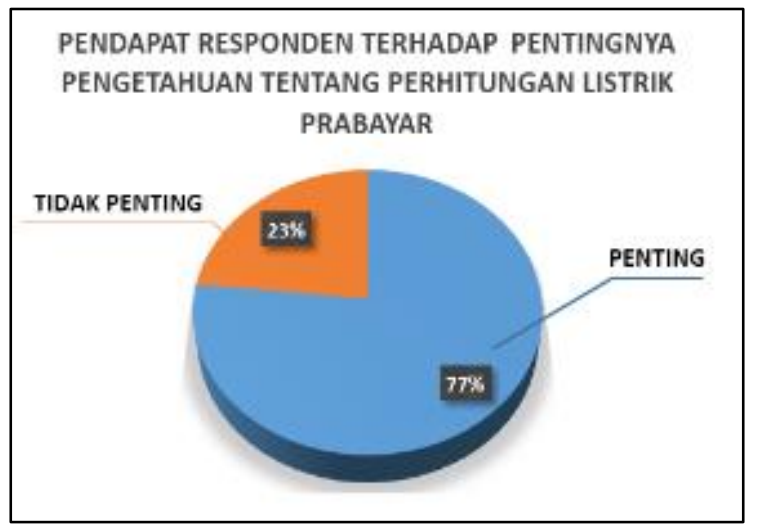

Gambar 5. Hasil Survei Pendapat Responden Terhadap Pentingnya Pengetahuan Tentang Penghitungan Listrik Prabayar

\subsection{Listrik Prabayar}

Listrik prabayar adalah program yang dijalankan oleh PT.PLN selaku penyedia dan penyalur energi listrik di Indonesia dimana konsumen harus membeli listrik jumlah tertentu sebelum bisa menggunakannya. Berbeda dengan sistem pascabayar dimana konsumen membayar tagihan listrik setelah menggunakannya. Secara umum, listrik prabayar dikenal masyarakat sebagai "token listrik". Pada prinsipnya, sistem listrik prabayar hampir mirip dengan sistem prabayar pulsa telepon seluler. Konsumen hanya perlu membeli pulsa listrik yang harganya mulai dari Rp 20.000,00 di konter terdekat, minimarket, atm, bahkan melalui e-commerce. Kemudian dari pembelian token listrik tersebut, konsumen akan memperoleh nomor token. Konsumen tinggal memasukkan nomor token pada KWH meter prabayar pada rumah mereka. Secara otomatis, KWH akan bertambah sesuai nominal listrik yang dibeli.

KWH meter adalah alat yang umum digunakan untuk mengukur energi listrik. Alat ini digunakan oleh Perusahaan Listrik untuk mendata dan menganalisa penggunaan energi listrik yang terpakai oleh konsumen. Dalam KWH meter terdapat komponen pengukuran daya yang terdiri dari komponen pengukur arus dan komponen pengukur tegangan. KWH Meter prabayar yaitu, alat yang dirancang oleh pihak PLN menggunakan KWH elektrik yang baru, sistem 
pengisian menggunakan pulsa. Untuk memulai berlangganan listrik kepada PLN, pelanggan harus tahu terlebih dahulu sistem yang diterapkan PLN untuk pelanggan listrik [5].

Listrik prabayar memiliki beberapa kelebihan dan kekurangan, antara lain:

Tabel 1. Kelebihan dan Kekurangan Listrik Prabayar [6]

\begin{tabular}{|c|c|}
\hline Kelebihan & Kekurangan \\
\hline $\begin{array}{l}\text { 1. Pelanggan bisa mengontrol } \\
\text { pemakaian listrik setiap hari. } \\
\text { 2. Pemakaian listrik dapat disesuaikan } \\
\text { dengan anggaran belanja. } \\
\text { 3. Tidak akan terkena biaya } \\
\text { keterlambatan. } \\
\text { 4. Jaringan luas pembelian listrik isi } \\
\text { ulang, bisa dibeli di loket } \\
\text { pembayaran listrik online. } \\
\text { 5. Tepat digunakan bagi Anda yang } \\
\text { memiliki usaha rumah kontrakan } \\
\text { atau kamar sewa (kos). } \\
\text { 6. Tidak akan terjadi kesalahan } \\
\text { pencatatan meteran listrik oleh } \\
\text { petugas. } \\
\text { 7. Sistem rahasia, } 20 \text { angka digit } \\
\text { pulsa listrik hanya bisa diisi ke } \\
\text { meteran listrik sendiri, tidak bisa } \\
\text { diisikan ke meteran lain. }\end{array}$ & $\begin{array}{l}\text { 1. Jika pulsa listrik habis di waktu } \\
\text { yang tidak terduga Anda harus siap } \\
\text { voucher cadangan, Bisa saja saat } \\
\text { membutuhkan listrik pulsa habis } \\
\text { dan listriknya mati. Tetapi ada } \\
\text { alarm pemberitahuan ketika listrik } \\
\text { tinggal } 10 \mathrm{kwh} \text {. } \\
\text { 2. Sering bermasalah saat akan } \\
\text { mengisi ataupun membeli, banyak } \\
\text { kasus jaringan internet sedang } \\
\text { down, maka Anda harus menunggu } \\
\text { sementara listrik di rumah Anda } \\
\text { sudah mati. } \\
\text { Meteran lebih sensitif dan mudah } \\
\text { rusak. }\end{array}$ \\
\hline
\end{tabular}

\subsection{Prakiraan Biaya Pelanggan Unit Meteran Prabayar}

Bagi pelanggan yang menggunakan unit meteran prabayar, pertama kali harus memenuhi dahulu kuota pemakaian daya secara satu bulan penuh sesuai dengan kapasitas daya listrik terpasang. Jadi, harus menghitung terlebih dulu total $\mathrm{kWh}$ yang dibutuhkan secara penuh berdasarkan kapasitas daya listrik terpasang supaya tidak kehabisan kuota saat pertengahan bulan.

Misalnya, untuk pelanggan dengan kapasitas daya 1.300 VA (6 Ampere) harus memenuhi kuota $\mathrm{kWh}$ pada unit meteran sebesar:

$=(1.300$ Watt $\times 24$ jam $) \times 30$ hari

$=31.200 \mathrm{Watt} \times 30$ hari

$=936.000 \mathrm{Watt}$ atau $936 \mathrm{kWh}$ per bulan

*Asumsi: 1 bulan $=30$ hari

Sama halnya dengan pelanggan dengan kapasitas daya 2.200 VA (10 Ampere), harus memenuhi kuota $\mathrm{kWh}$ pada unit meteran sebesar:

$=(2.200$ Watt $\times 24$ jam $) \times 30$ hari

$=52.800$ Watt $\mathrm{x} 30$ hari

$=1.584 .000 \mathrm{Watt}$ atau $1.584 \mathrm{kWh}$ per bulan

dan juga berlaku untuk pelanggan meteran prabayar yang menggunakan kapasitas berbeda lainnya. Setelah pemenuhan kuota selama sebulan penuh telah dikerjakan, hitung nilai per $\mathrm{kWh}$ 
dari total kuota yang telah diisikan. Misalnya, pada pelanggan 1.300 VA untuk mendapatkan total kuota sebesar $936 \mathrm{kWh}$ perbulan.

Contoh kasus: Ada konsumen rumah tangga yang daya listriknya 1.300volt ampere (VA). Ia membeli token (pulsa) listrik Rp 100.000. Berapa kWh listrik yang ia dapatkan? Apa saja yang diperhitungkan dalam pembelian token listrik tersebut?

- Administrasi bank Rp 1.600 (Ini tergantung bank/koperasinya).

- Biaya materai Rp 0 (karena jumlah pembelian token listrik hanya Rp 100.000)

- Pajak Penerangan Jalan (PPJ) Rp 2.306. Di sini masing-masing daerah berbeda-beda, Untuk DKI Jakarta PPJ-nya 2,4\% dari tagihan listrik

- Beli token listrik Rp 100.000 artinya akan kena potongan biaya administrasi dan PPJ (Rp $1.600+\operatorname{Rp} 2.306)=\operatorname{Rp} 96.094$

- Sisa rupiah Rp 96.094 tersebut dibagi Rp 1.352/kWh (tarif listrik untuk golongan 1.300 VA) hasilnya 71,08 kWh.

\subsection{Simulasi Perhitungan Pemakaian Listrik}

Untuk dapat menghitung berapa pemakaian listrik sebulan, pertama harus mencatat peralatan listrik apa saja yang anda gunakan. Catat juga berapa besar daya listrik dari masingmasing peralatan listrik tersebut dalam satuan Watt. Biasanya besar daya listrik sudah tertera pada masing-masing peralatan listrik yang kita miliki. Lalu juga harus mencatat berapa lama kira-kira peralatan listrik tersebut anda nyalakan dalam satuan jam. Setelah kita mendapatkan data dari beberapa hal diatas, selanjutnya kita mulai melakukan perhitungan.

\section{Contoh:}

Jika di rumah kita memiliki berbagai peralatan listrik terpasang, antara lain:

- Lampu untuk penerangan sebanyak 10 buah Lampu dengan daya masing-masing 30 watt

- Pendingin ruangan (AC) sebanyak 2unit dengan daya masing-masing $1 \mathrm{PK}$ (1 pk $=1$ tenaga kuda, sama dengan 750 watt).

- 1set Televisi dan digital parabola sebesar 100 watt.

- 1unit setrika 300 watt.

- 1 unit mesin cuci 350 watt.

- 1 unit Lemari es 300 watt.

Rincian lama pemakaian masing-masing alat listrik dalam satu hari:

- 10 buah Lampu menyala dari jam 18.00 sampai dengan 06.00, berarti lama pemakaian adalah: 12jam, Maka total kwh 10 buah lampu adalah: 10 buah x 30watt x 12 jam $=360$ watt

- 2 buah pendingin ruangan (AC) menyala dari jam 12.00 sampai dengan 24.00, berarti lama pemakaian adalah: $12 \mathrm{jam}$, Maka total kwh 2 unit pendingin ruangan (AC) adalah: $2 \mathrm{unit} \mathrm{x}$ 750 watt $\mathrm{x} 12 \mathrm{jam}=18.000$ watt

- Televisi dan digital parabola menyala dari jam 06.00 sampai dengan 22.00, berarti lama pemakaian adalah 16jam, Maka total kwh televisi dan digital parabola adalah: 1 set $\mathrm{x}$ 100 watt $\times 16$ jam $=1.600$ watt

- Setrika dipakai setiap hari selama 2 jam, Maka total kwh setrika adalah: 1unit x 300watt x 2 jam $=600$ watt

- Mesin cuci dipakai setiap hari selama 2 jam, Maka total kwh mesin cuci adalah: 1unit x 350 watt $\times 2$ jam $=700$ watt 
- Lemasi es menyala sepanjang hari, atau selama 24 jam, Maka total kwh lemari es adalah: 1unit $\mathrm{x} 300$ watt $\mathrm{x} 24=7200$ watt

Total daya listrik yang kita pakai setiap harinya adalah: $360 \mathrm{watt}+18.000 \mathrm{watt}+1.600 \mathrm{watt}+$ 600 watt $+700 w a t t+7200$ watt $=28.460$ watt. Karena nilai daya listrik total yang kita butuhkan adalah dalam satuan KW (1.000 Watt), maka untuk mendapatkan nilai KWH, maka hasil total daya diatas harus dibagi 1000. Maka 28.460watt dibagi 1000 sama dengan 28,46 KW

Jika alat listrik dan lama pemakaian alat listrik kita sesuai dengan contoh perhitungan diatas, maka sekarang kita sudah mendapatkan hasilnya, bahwa pemakaian daya listrik kita setiap hari adalah 28,46 KWH Dengan data diatas kita dapat menghitung berapa rupiah tagihan listrik Anda dengan mengkalikan total KWH dengan TDL (tarif dasar listrik) yang terpasang. Jika tarif dasar listrik dengan daya 1300watt adalah Rp 1.410 Maka biaya tagihan listrik anda sehari adalah: 28,46 kwh x Rp $1410=\operatorname{Rp} 40.128,6$ perhari.

Setelah kita mendapatkan pemakaian KWH selama satu hari, sekarang kita tinggal mengalikan dengan berapa hari dalam sebulan Jika sebulan adalah 30 hari, maka biaya listrik sehari tadi dikali dengan 30 hari. Jika dalam sebulan pemakaian listrik Anda sesuai atau sama dengan perhitungan pemakaian setiap harinya, maka tagihan listrik Anda sebulan adalah:

Rp 40.128,6 x 30 hari $=$ Rp 1.203.858,00

\section{KESIMPULAN}

Kegiatan Program Kemitraan Masyarakat (PKM) berupa sosialisasi dan simulasi perhitungan listrik prabayar untuk masyarakat Petukangan Utara, Jakarta Selatan telah berhasil dilaksanakan pada tanggal 9 Mei 2018. Sebelum dilaksanakan sosialisasi, tim PKM melakukan survei untuk mengetahui tingkat pengetahuan masyarakat terhadap cara perhitungan listrik prabayar. Hasil survei menunjukkan bahwa lebih dari $60 \%$ responden belum mengetahui cara menghitung listrik prabayar. Setelah diberikan sosialisasi mengenai hal tersebut, peserta dapat mengetahui serta mengaplikasikan perhitungan Listrik Prabayar agar tidak terjadi pemborosan anggaran belanja rumah tangga sehingga menjadi masyarakat yang bijak dalam menggunakan energi listrik.

Kegiatan sosialisasi ini juga sebagai wadah bagi tim PKM untuk memenuhi salah satu Tri Dharma Perguruan Tinggi yaitu mengadakan Program Kemitraan Masyarakat. Bagi STT PLN, kegiatan sosialisasi ini telah meningkatkan citra STT-PLN di masyarakat umum dalam rangka meningkatkan kualitas hidup masyarakat, serta mempererat hubungan antara civitas akademika STT-PLN dengan warga masyarakat.

\section{SARAN}

Saran yang dapat diberikan untuk program sosialisasi selanjutnya adalah penambahan materi yang diberikan kepada peserta mengenai cara memilih peralatan listrik rumah tangga yang lebih hemat listrik. Materi tersebut dipilih atas masukan dan saran dari peserta sosialisasi.

\section{UCAPAN TERIMA KASIH}

Penulis mengucapkan terima kasih kepada STT-PLN Jakarta dan LPPM atas kesempatan kepada tim PKM dan dukungan baik moril maupun materiil serta pendanaan sehingga kegiatan PKM dapat terlaksana dengan baik. 


\section{DAFTAR PUSTAKA}

[1] A. Budianto and H. Saragih, "Penerapan system Listrik PLN Prabayar dengan Penggunaan dan Pengoperasian KWH Meter Prabayar secara IT dalam E-payment Sistem Pulsa Listrik," Jurnal Sistem Informasi Univ. Indonesia, vol. VII, no. 2, pp. 77-82, Oktober 2011.

[2] P. Rhamadani, Penggunaan Meter Prabayar oleh PT. Perusahaan Listrik Negara (PLN) (Persero) Sebagai Teknik Pencegahan Pencurian Listrik Secara Situasional, Depok: Skripsi: Universitas Indonesia, 2012.

[3] Ismono, "Modern, Terkendali, dan Hemat: Serba-serbi Listrik Prabayar (1)," 2010. [Online]. Available: http://nova.grid.id/read/07610967/serba-serbi-listrik-prabayar1?page $=$ all. [Accessed 6 Februari 2019].

[4] A. Azwar, "Listrik Prabayar Dilihat dari Perilaku Konsumen," Jurnal Ekonomi dan Bsinis, vol. XI, no. 1, pp. 35-42, 2012.

[5] S. Nuraita, "Pusat Jurnal Ilmiah Online Sekolah Tinggi Teknik Harapan," [Online]. Available: http://journal.stth-medan.ac.id/mahasiswa/index.php/doc_download/317v1197-analisa-perbandingan-kwh-meter-prabayar-dengan-nonprabayar-di-lihat-dari-sisikeekonomisannya-di-pt-pln-persero. [Accessed 12 Desember 2018].

[6] Tidak diketahui, "Perbedaan Listrik Prabayar dengan Listrik Pascabayar," [Online]. Available: http://www.duta-pulsa.co.id/listrik-prabayar-vs-pascabayar/. [Accessed 12 Desember 2018]. 